\title{
M.A. DOUBLE DEGREE IN GLOBAL COMMUNICATION YEAR-END STUDENT PRESENTATIONS
}

The students in the program have each completed an extended essay after their first year of studies at SFU. They are going to start their final year in the program at the Communication University of China (CUC) in Beijing. The students will give oral presentations based on their essays. Dr. Yuezhi Zhao, Founding Program Director \& Professor in SFU School of Communication will moderate the event.

\section{AUGUST 7,2015 (FRIDAY) • 9:00 AM - 4:00 PM HCC 7000 (EARL \& JENNIE LOHN POLICY ROOM)}

\begin{tabular}{|c|c|}
\hline 9:00 AM & Welcome \& Program Overview - Dr. Yuezhi Zhao \\
\hline $9: 15 \mathrm{AM}$ & Students' Presentations - Part I* \\
\hline 10:30 AM & Coffee Break - Light refreshments will be served \\
\hline 10:45 AM & Students' Presentations - Part II ** \\
\hline 12:00 PM & Lunch \\
\hline 1:00 PM & $\begin{array}{l}\text { "Networking the nation: communication and economic } \\
\text { restructuring in China" - Guest speaker: Dr. Yu Hong }\end{array}$ \\
\hline 2:30 PM & Networking \\
\hline
\end{tabular}

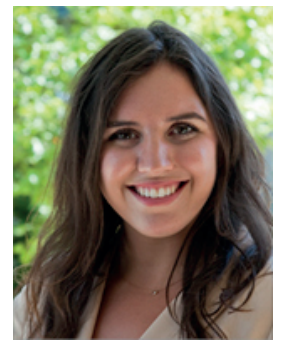

Kirsten Berry

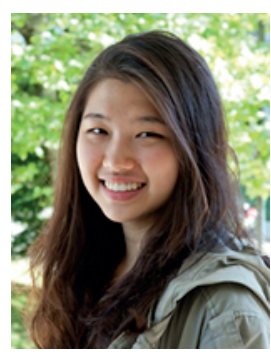

Beatrice Chao

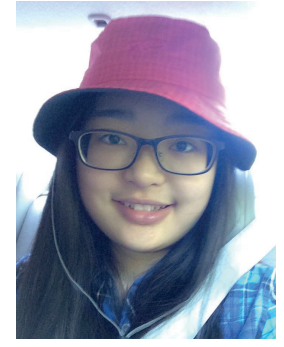

Wei Huang

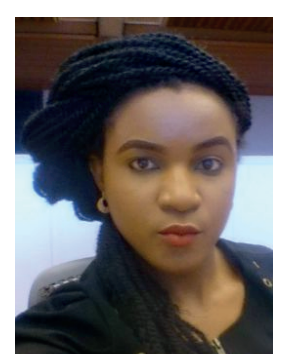

Lucia Inyang
* PART I STUDENT PRESENTERS

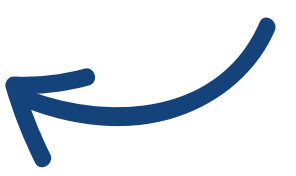

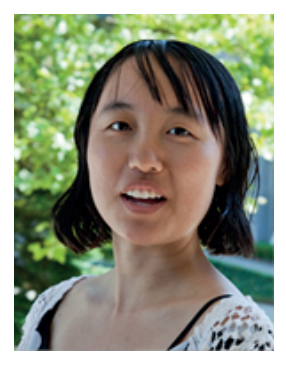

Hatty Liu

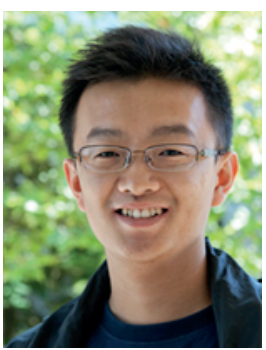

Yu Song

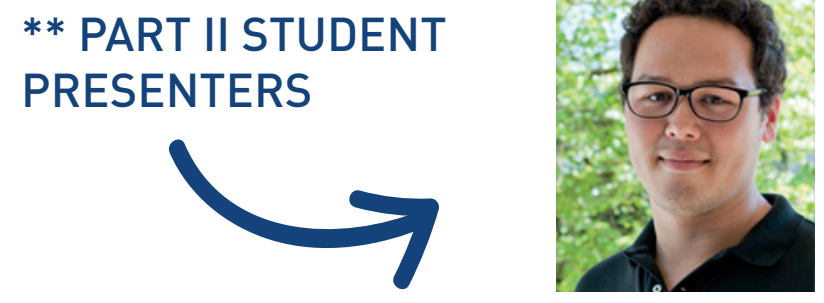

Shawn Jones

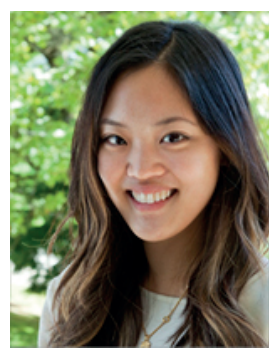

Amanda Liao 


\section{GUEST SPEAKER
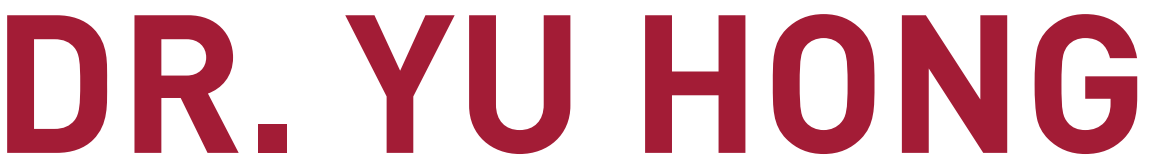

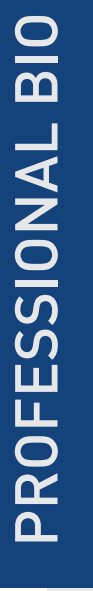

Yu Hong is an assistant professor in the

School of Communication at USC Annenberg. She got her Ph.D. in Communication from the University of Illinois at Urbana-Champaign.

Her research areas include:

- ICTs and development

- Political economy of global communication

- China's information and communications industry, information labor, and information

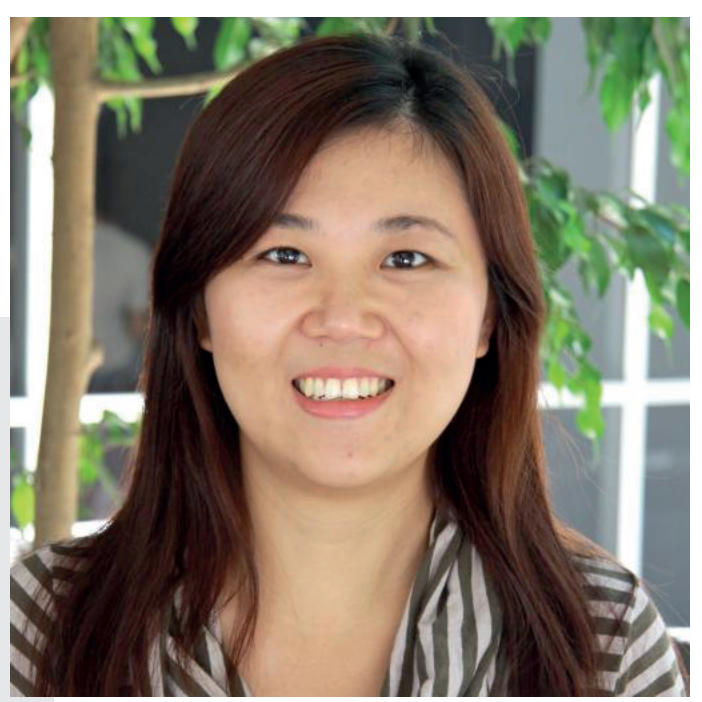
society theories

\section{USCAnnenberg}

School for Communication and Journalism

\section{"Networking the nation: communication and economic restructuring in China"}

Dr. Yu Hong will talk about how communications, across its entire range from telecommunications to broadband and from wireless networks to digital media, are becoming a state-designated growth engine intended to rejuvenate China's political economy out of the stagnation that has afflicted the entire global capitalist system with which China is deeply integrated.
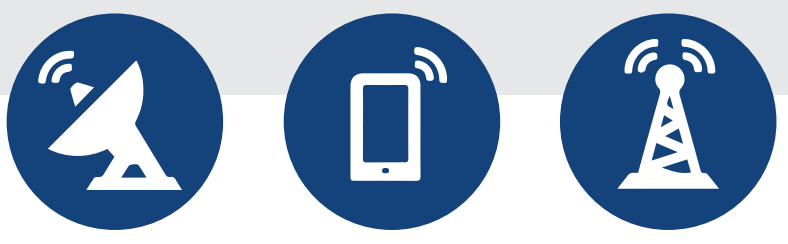

annenberg.usc.edu/faculty/communication/yu-hong 